\section{International Scientific Journal Theoretical \& Applied Science}

p-ISSN: 2308-4944 (print) e-ISSN: 2409-0085 (online)

Year: $2014 \quad$ Issue: $11 \quad$ Volume: 19

Published: $30.11 .2014 \quad$ http://www.T-Science.org
Aleksandr Grigorievich Sokolov Doctor of technical sciences, professor, Professor Kuban State Technological University, Russia sag-51@,bk.ru

Eduard Eduardovich Bobylyov Graduate student Kuban State Technological University, Russia ebobylev@mail.ru

SECTION 7. Mechanics and machine construction.

\title{
DIFFUSION METALLIZATION OF TUNGSTEN CARBIDES AS A WAY TO IMPROVE THE QUALITY OF PROCESSING OF HARD ALLOYS
}

Abstract: The analysis of the influence of deposition of copper-nickel coatings by the diffusion metallization from environment of the fusible liquid metal solutions at resistance of alloy carbide inserts of type VC and TC, and to the quality of the processing of hard alloy with high viscosity, has been performed.

Key words: Tungsten carbides; diffusion metallization; cutting; wear-resistant coatings.

Language: Russian

Citation: Sokolov AG, Bobylyov EE (2014) DIFFUSION METALLIZATION OF TUNGSTEN CARBIDES AS A WAY TO IMPROVE THE QUALITY OF PROCESSING OF HARD ALLOYS. ISJ Theoretical \& Applied Science 11 (19): 55-58. doi: http://dx.doi.org/10.15863/TAS.2014.11.19.11

\section{УДК 67.017}

\section{ДИФФУЗИОННАЯ МЕТАЛЛИЗАЦИЯ ТВЁРДЫХ СПЛАВОВ КАК СПОСОБ ПОВЫШЕНИЯ КАЧЕСТВА ОБРАБОТКИ ТРУДНООБРАБАТЫВАЕМЫХ СПЛАВОВ}

Аннотация: Проведен анализ влияния нанесения никель-медных покрытий путем диффузионной металлизации из среды легкоплавких жидкометаллических растворов на стойкость твердосплавных пластин из сплавов типа ВК и ТК, а также на качество обработки труднообрабатываемых сплавов повышенной вязкости.

Ключевые слова: Твёрдый сплав, диффузионная металлизачия, обработка резанием, износостойкие покрытия.

Высокопроизводительная обработка материалов резанием достигается применением для обработки твердосплавного инструмента.

Несмотря на то, что общее количество режущего инструмента из твердых сплавов не превышает 25\%, этим режущим инструментом снимается до $65 \%$ стружки от общего объема стружки, снимаемого инструментом, изготовленным из всех применяемых инструментальных материалов.

Однако интенсификация производства, применение в конструкциях новых труднообрабатываемых материалов и автоматизация процесса обработки предъявляют все более высокие требования к стойкости, надежности инструмента и качеству обработки резанием, вследствие этого проблема повышения эксплуатационного ресурса твердосплавного инструмента является весьма актуальной не только у нас в стране, но и во всем мире. характеристик твердосплавного инструмента, как показал анализ, проведенный в 1-й главе диссертационной работы, ведется в двух направлениях.

Первый - это традиционный путь, заключающийся в оптимизации состава твердого сплава путем применения в качестве связующего многоэлементных твердых растворов, а в качестве твердой фазы - карбидов, карбонитридов, нетрадиционных для этих сплавов металлических элементов $(\mathrm{Cr}, \mathrm{Hf}, \mathrm{Zr}$ и др.).

Второе направление - это изменение механических характеристик (в частности, износостойкости) поверхностных слоев режущей части инструмента за счет изменения их состава, которое осуществляется путем нанесения покрытий. 
Второе направление интенсивно развивается ведущими фирмами мира, такими как Sandvik Coromant (Швеция), Hertel (Германия), Kennametal (США), Mitsubishi (Япония) и др., а также российскими производителями: Кировоградский инструментальный завод, Sandvik MKTC, ЗАО "Холдинговая компания "Инструментальные заводы" и др., занимающимися производством твердосплавного инструмента.

Для нанесения покрытий на твердосплавный инструмент в настоящее время наиболее распространенными являются два способа: первый - это метод химического осаждения CVD и его усовершенствованный метод низкотемпературного осаждения MT-CVD, и второй - метод физического осаждения PVD.

Покрытия, получаемые данными методами, представляют собой слои с кристаллической структурой из химически инертных и тугоплавких соединений, таких как карбид титана, нитрид титана, оксид алюминия, циркония и др. Нанесение покрытий на твердые сплавы позволяет значительно увеличить скорость резания, a, следовательно, и производительность процесса обработки, повысить стойкость инструмента, его геометрическую стабильность и качество обработки. Однако покрытия, нанесенные методами CVD и PVD, имеют ряд существенных эксплуатационных и технологических недостатков. К числу этих недостатков относятся, прежде всего, низкая адгезия, это особенно характерно для покрытий, получаемых методами CVD, высокая хрупкость, которая приводит к снижению прочностных свойств твердого сплава и накладывает ограничения на остроту режущей кромки инструмента, а затупленная режущая кромка - это возрастающие усилия в зоне резания и выделение тепла. Кроме этого, нитридные, карбидные, оксидные покрытия обладают низкой теплопроводностью, что также способствует повышению температуры в зоне резания, а разогрев в зоне резания приводит к снижению стойкости инструмента и возникновению наростообразования на инструменте, что ведет к снижению качества обработки.

Кроме этого, способы химического и физического осаждения требуют применения сложного, дорогого, энергозатратного оборудования, и технологические процессы связаны с использованием агрессивных, ядовитых сред.

Решение вышеуказанных проблем может быть достигнуто применением для нанесения покрытий технологии диффузионной металлизации твердых сплавов из среды легкоплавких жидкометаллических растворов. В частности, предлагается наносить на поверхность твердосплавных пластин двухкомпонентные никель-медные покрытия, обладающие сочетанием уникальных свойств, таких как высокая вязкость и износостойкость. Диффузионные никель-медные покрытия наносились на исходно непокрытые пластины путем их диффузионной металлизации с применением упомянутой выше технологии диффузионной металлизации из среды легкоплавких жидкометаллических растворов [1].

Металлизация проводилась в свинцоволитиевом расплаве, в котором были растворены никель и медь. Покрытия наносились путем погружения и выдержки заданное время твердосплавных пластин в ванне с легкоплавким расплавом. Процесс осуществлялся в модернизированной электропечи СГВ -2,4-2/15И3, позволяющей проводить, нагрев изделий в среде инертных газов.

Модернизация печи была проведена с целью обеспечения возможности нанесения покрытий в открытой жидкометаллической ванне. Нанесение покрытий проводилось в интервале температур от 900 до $1220^{\circ} \mathrm{C}$ в изотермическом цикле и в цикле термоциклирования. Длительность выдержки варьировалась от 10 минут до 30 часов.

Покрытые пластины из твердых сплавов подвергались

исследованиям на исследовательском металлографическом микроскопе AxioObferever A1.m фирмы «Zeiss», промеру микротвердости на электронном твердомере Dura Scan 80. Распределение элементов в приповерхностных слоях твердосплавных пластин - покрытий и прилегающих к ним участков определялось методом рентгеноспектрального микроанализа на микроанализаторе «Camebax micro», оснащенном энергодисперсионным спектрометром «INCA ENERGY 350», при энергии электронов зонда 15 кэВ. Локальность определения 2 мкм.

Фазовый состав по толщине диффузионного слоя определялся методом рентгенофазного структурного анализа на дифрактометре ДРОН УM2.

Исследования по оценке влияния состава и свойств поверхностных слоев твердосплавного инструмента на качество обработки проводились путем точения алюминиевого сплава АМг6 и нержавеющей стали $12 \mathrm{X} 18 \mathrm{H} 10 \mathrm{~T}$, а также титанового сплава ВТ1-00. Заготовки из алюминиевого сплава были в виде прутка диаметром 50 мм, а заготовки из нержавеющей стали - в виде тонкостенной трубы (толщина стенки 2мм) диаметром 50мм, заготовка из титанового сплава представляла собой пруток диаметром 20мм. Токарная обработка проводилась при скоростях резания $60 \mathrm{M} / \mathrm{c}, 80$ м/c, 100 м/с, подачей 0,14мм/об. Оценка 
стойкости резцов проводилась путем точения прутка диаметром 60мм из стали Х12МФ в состоянии поставки. За период стойкости принималось время, за которое резец терял режущие свойства.

Как показали результаты исследования, диффузионная металлизация твердых сплавов типов ВК и ТК из среды легкоплавких жидкометаллических растворов никеля и меди в свинцово-литиевом расплаве приводит к формированию на их поверхности двухслойного диффузионного покрытия (рис.1). Наружный слой покрытия представляет собой твердый раствор никеля, меди и кобальта. Толщина этого слоя зависит от режимов металлизации и лежит в пределах 10...25мкм, а его исходная микротвердость поверхностного слоя - 30003200МПа. Под твердорастворным поверхностным слоем на сплавах типа ТК формируется слой повышенной твердости. Микротвердость этого слоя составляет 21000 МПа, т.е. более чем на 2 тыс. МПа выше твердости основы. После этого наблюдается монотонное снижение твердости до твердости основы - $\mathrm{H}_{50}=18660$ МПа.

Фотографии пластин из сплава Т15К6 с никель-медным покрытием и без него представлены на рисунке 2.

Высокая вязкость никель-медных покрытий значительно повышает и вязкость поверхностных слоев твердых сплавов, что позволяет создавать острые режущие кромки на инструменте и значительно снизить их склонность к выкрашиванию при возникновении в процессе резания ударных нагрузок. Низкий коэффициент трения, высокая теплопроводность никельмедного покрытия, острота режущей кромки позволяют исключить наростообразование на инструменте и, таким образом, повысить качество обработки и ее производительность.

Сравнительные испытания режущих свойств инструмента с твердосплавными пластинами, без покрытий, с PVD покрытиями (ТУ 19-4205-772004) на базе нитрида титана и с никель-медными диффузионными покрытиями, проведенные при токарной обработке, показали, что нанесение покрытий на твердосплавный инструмент обеспечивает значительное повышение качества обработки. Так, при точении алюминиевого сплава АМц резцами, оснащенными пластинами c PVD покрытиями, наблюдается снижение шероховатости поверхности по сравнению с обработкой резцами, у которых пластины были без покрытия. При скоростях резания 80 и 100 м/мин резцами с PVD покрытиями относительно непокрытых параметр шероховатости обработанной поверхности $\mathrm{Ra}$ снижается в 2,4раза. Однако, обработка того же сплава резцами с диффузионными никель-медными покрытыми обеспечивает более существенное повышение качества обработки.

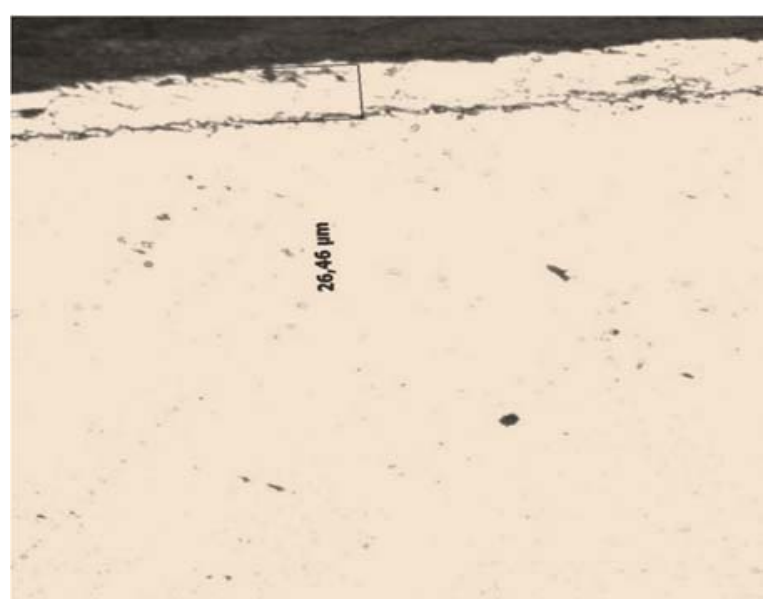

Рисунок 1 - Вид нетравленого металлографического шлифа сплава Т15К6 с никель-медным покрытием. X500.

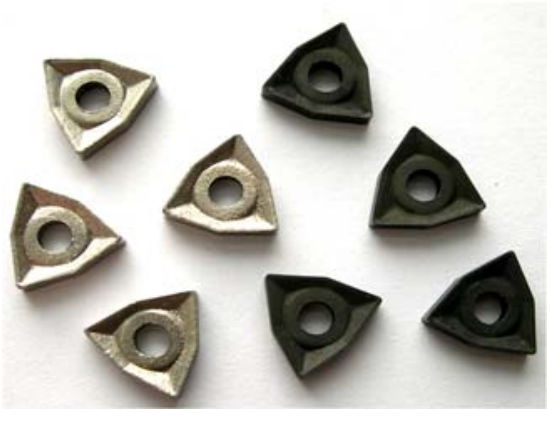

Рисунок 2 - Твердосплавные шестигранные пластины WNUM-080404 с никель-медными покрытиями (светлые) и без покрытий (темные).

Сравнение параметров шероховатости обработанных поверхностей резцами, оснащенными пластинами с диффузионными никель-медными покрытиями и без покрытый, при скоростях резания 80 и 100 м/мин показывает, что никель-медные покрытия обеспечивают снижение параметра шероховатости обработанной поверхности Ra в 4,3 раза. Так, при скорости резания $100 \mathrm{~m} / \mathrm{Mин} \mathrm{R}_{\mathrm{a}}$ покр. $\mathrm{Ni}+\mathrm{Cu}=1,57$ мкм, a $\mathrm{R}_{\mathrm{a} \text { непокр. }}=6,71$ мкм.

Снижение шероховатости обработанных поверхностей резцами, оснащенными пластинами с диффузионными никель-медными покрытиями, по сравнению с резцами с пластинами с PVD покрытиями при скоростях резания 80 и 100 м/мин составляет 1,8 раза, т.е. $180 \%$. 
Таким образом, нанесение диффузионных никель-медных покрытий на твердые сплавы обеспечивает значительное улучшение качества чистовой обработки алюминиевых сплавов. Данное улучшение качества обработки, как показывает анализ состояния передней поверхности резца, связан с отсутствием наростообразования на этой поверхности на твердосплавных пластинах с никель-медным покрытием.

Улучшение качества обработки за счет нанесения покрытий на твердосплавный инструмент наблюдается и при обработке титана и его сплавов. Исследования по оценке влияния типа покрытия на шероховатость обработанных поверхностей, проведенные на сплаве ВТ1-00, показали, что шероховатость обработанной поверхности зависит от скорости резания. При скорости резания 30м/мин твердосплавные пластины c PVD покрытием обеспечивают незначительное снижение шероховатости поверхности по сравнению с пластинами без покрытий, в то время как шероховатость обработанной поверхности после применения пластин с никель-медными покрытиями снизилась в 2,4 раза. При скорости резания 40м/мин наблюдается небольшое повышение шероховатости поверхности, обработанной пластинами с PVD покрытием, по сравнению с пластинами без покрытий. Никель-медные покрытия на данном режиме обеспечивают снижение шероховатости обработанной поверхности относительно пластин с PVD покрытиями в 2,75 раза.

Дальнейшее увеличение скорости резания, в частности, до 50м/мин обеспечивает улучшение качества обработки резцами, имеющими PVD покрытия и никель-медные покрытия.

Аналогичные результаты наблюдаются при обработке аустенитной нержавеющей стали. Так, например, при обработке тонкостенной трубы диаметром 50мм с толщиной стенок 2 мм из аустенитной нержавеющей стали 12X18H10T вследствие низкой жесткости стенок наблюдается снижение качества обработанной поверхности не только на микро-, но и на макроуровне. Наростообразование на рабочих поверхностях резцов с пластинами без покрытий и с PVD покрытиями вызывают образования на обработанной поверхности шагрени. В тоже время обработка аналогичной твердосплавной пластиной с никель-медным покрытием обеспечивает высокое качество обработанной поверхности вплоть до толщины стенки трубы 0,5 мм. Скорость резания при обработке составляла 140 м/мин, глубина резания 0,5 мм, подача $0,14 \mathrm{mм} /$ об.

Таким образом, нанесение никель-медных покрытий на твердые сплавы обеспечивают значительное повышение качества обработки вязких труднообрабатываемых сплавов.

\section{References:}

1. Sokolov AG, Artem'ev VP (2006) Povyshenie rabostoposobnosti instrumena metodami diffuzionnoy metallizatsii. Rostov-na-Donu: Izd-vo SKNTs VSh, 228.

2. (2012) Patent na izobretenie №2451108 RF, MPK S 23 S10/26 (2006.01). Sposob obrabotki instrumenta iz stali, ili tverdogo splava. AG Sokolov (RF), Mansia Salakhaldin (RF) Zayavleno 04.10.2010; opubl. 20.05.2012, Byul No. 14

3. (2014) Patent na izobretenie №2509173, MPK S 23S 10/26; S23S 2/10 (2006.01). Sposob obrabotki tverdosplavnogo instrumenta. A.G. Sokolov (RF)- Zayavleno 12.02.2013; opubl. 10.03.2014, Byul No. 7

4. Carter GF (1968) Diffusion coating fromed in molten calcium impart high corrosion resistance. - Metal Progr., 93 No. 6, pp.11231128.

5. Carter GF, Fleming RA (1968) Diffusion coatings formed in molten calcium systems. Reactions in $\mathrm{Ca}-\mathrm{Fe}-\mathrm{Cr}$ systems. J. LessCommon Metals, 14 No.2, pp. 328 - 336.
6. Miyooski Yasuhiko, Kado Satoshi, Otoguro Yasuv, Muda Noboru (1975) Bosyoku gyutsu. Gross. Eng., 24, No.4, pp. 177-182.

7. Sokolov AG (2006) Vliyanie sostava transportnogo rasplava na protsess formirovaniya pokrytiy pri diffuzionnoy metallizatsii iz sredy zhidkometallicheskikh rastvorov. V kn.: Nauchnaya mysl' Kavkaza. Rostov-Donu, No.2, pp. 139-157.

8. Sokolov AG, Artem'ev VP (2007) Vliyanie tekhnologicheskikh faktorov i khimicheskogo sostava staley na strukturu i svoystva diffuzionnykh nikel'soderzhashchikh pokrytiy. MiTO, No.4.

9. Maksimov M (2010) Iznosostoykie pokrytiya kak dvizhitel' protsessa v tekhnologii instrumental'nykh materialov i sovremennoy metalloobrabotki. NanoWeek - 2010. - № 106.

10. Vereshchaka AS, Tabakov VP (1998) Fizicheskie osnovy protsessa rezaniya i iznashivaniya rezhushchego instrumenta $\mathrm{s}$ iznosostoykimi pokrytiyami. Ul'yanovsk, 144 